\title{
Prevalence of Smoking among Iranian Adults: Findings of the National STEPs Survey 2016
}

\author{
Mehdi Varmaghani, PhD',2; Farshad Sharifi, PhD'; Parinaz Mehdipour, MSc ${ }^{2,4}$; Ali Sheidaei, MSc'; Shirin Djalalinia, PhD ${ }^{2,5}$; Kimiya Gohari, \\ MSc ; Mitra Modirian, MD²; Forough Pazhuheian, MSc ${ }^{2}$; Niloofar Peykari, PhD ${ }^{2,7}$; Rosa Haghshenas, BSc ${ }^{2}$; Alireza Khajavi, MSc ${ }^{8,2}$; Hossein \\ Zokaei, MSc²; Ghobad Moradi, PhD ${ }^{9}$; Alireza Mahdavihezaveh, MD ${ }^{10}$; Farshad Farzadfar, MD, MPH, MHS, D.Sc ${ }^{2,11}$ \\ ${ }^{1}$ Social Determinants of Health Research Center, Mashhad University of Medical Sciences, Mashhad, Iran \\ ${ }^{2}$ Non-Communicable Disease Research Center, Endocrinology and Metabolism Population Sciences Institute, Tehran University of Medical \\ Sciences, Tehran, Iran \\ 'Elderly Health Research Center, Endocrinology and Metabolism Population Sciences Institute, Tehran University of Medical Sciences, Tehran, \\ Iran \\ ${ }^{4}$ Department of Epidemiology and Biostatistics, School of Public Health, Tehran University of Medical Sciences, Tehran, Iran \\ ${ }^{5}$ Deputy of Research and Technology, Ministry of Health and Medical Education, Tehran, Iran \\ ${ }^{6}$ Department of Biostatistics, Faculty of Paramedical Sciences, Shahid Beheshti University of Medical Sciences, Tehran, Iran \\ ${ }^{7}$ Ministry of Health and Medical Education, Tehran, Iran \\ ${ }^{8}$ Student Research Committee, Faculty of Paramedical Sciences, Shahid Beheshti University of Medical Sciences, Tehran, Iran \\ ${ }^{9}$ Social Determinants of Health Research Center, Kurdistan University of Medical Sciences, Sanandaj, Iran \\ ${ }^{10}$ Deputy of Health, Ministry of Health and Medical Education, Tehran, Iran \\ "Endocrinology and Metabolism Research Center, Endocrinology and Metabolism Clinical Sciences Institute, Tehran University of Medical \\ Sciences, Tehran, Iran
}

\begin{abstract}
Background: Tobacco smoking is one of the most important avoidable causes of mortality from non-communicable diseases (NCDs). This study aimed to report the crude and standardized prevalence of current, ever, and secondhand smoking at national and provincial levels.

Methods: This study was performed through an analysis of the results of the STEPs survey 2016, which was conducted as a cross-sectional national study. The samples were selected via multistage cluster sampling and they were representative of general population aged $\geq 18$ years in all provinces of Iran. All the data were analyzed via survey analysis while considering population weights. Age-standardized prevalence was also calculated for the Iranian national population in 2016 and the World Health Organization (WHO) Population 2000-2025.

Results: A total of 29963 subjects aged $\geq 18$ years from all provinces of Iran, except for Qom, participated in this study. The age standardized prevalence of current tobacco smoking among adult males and females were $24.4 \%(95 \% \mathrm{Cl}: 23.6 \%-25.1 \%)$ and $3.8 \%(95 \% \mathrm{Cl}: 3.5 \%-4.1 \%)$, respectively. Among the participants, the majority of the current smokers were among those aged $45-54$ years $(14.5 \% ; 95 \% \mathrm{Cl}: 13.6 \%-15.5 \%)$. With increase in age, the prevalence of secondhand smoking decreased to $34.8 \%$ (95\% Cl: $33.3 \%-36.7 \%$ ) among people aged $18-24$ years and to $22 \cdot 6 \%$ (95\% Cl: $21.0 \%-24.3 \%$ ) among subjects over 70 years. Conclusion: The result of the study can be used to inform policy makers about the status of smoking and help them to design policies for setting rules on and limiting the import of cigarettes and their components to the country.

Keywords: Iran, Prevalence, Second hand smoke, Tobacco Smoking

Cite this article as: Varmaghani M, Sharifi F, Mehdipour P, Sheidaei A, Djalalinia S, Gohari K, et al. Prevalence of smoking among Iranian adults: findings of the national STEPs survey 2016. Arch Iran Med. 2020;23(6):369-377. doi: 10.34172/aim.2020.29.
\end{abstract}

Received: May 12, 2019, Accepted: January 18, 2020, ePublished: June 1, 2020

\section{Introduction}

Policy makers in both developed and developing countries need appropriate information about non-communicable diseases (NCDs) risk factors at national and sub-national levels. ${ }^{1}$ Analysis of risk factors for poor health can provide information that facilitate the implementation of policies designed for prioritization, prevention, intervention, and control of NCDs. ${ }^{2}$ Nevertheless, policy makers do not have access to enough reliable information about NCDs risk factors in developing countries. ${ }^{3}$ The World Health Organization (WHO) has recommended countries to reduce the rate of death from four major NCDs including cardiovascular diseases (CVDs), respiratory diseases, diabetes, and cancers by around $25 \%$ by 2025 via reducing related risk factors, particularly smoking. ${ }^{4}$

Tobacco smoking is one of the most important avoidable causes of death from NCDs. ${ }^{5}$ As estimated, the smoking of tobacco and its derivatives is the leading cause of death in

*Corresponding Author: Farshad Farzadfar, MD, PhD; Non-communicable Diseases Research Center, Endocrinology and Metabolism Population Science Institute, Tehran University of Medical Sciences, Tehran, Iran; and Endocrinology and Metabolism Research Center, Endocrinology and Metabolism Research Institute, Tehran University of Medical Sciences, Tehran, Iran. Tel: +98-21-88631293. Email: f-farzadfar@tums.ac.ir 
over six million people across the world annually. Moreover, it is predicted that by 2030 , tobacco smoking will have led to 8.3 million deaths annually. ${ }^{6}$ According to the $\mathrm{WHO}$, approximately $80 \%$ of mortality from tobacco smoking will occur in developing countries. ${ }^{7}$ Furthermore, about $4 \%$ and $13 \%$ of disability-adjusted life years (DALYs) in developed and developing countries, respectively, are attributable to smoking. ${ }^{8,9}$ Moreover, based on the results of a recent study, smoking is still one of the five major risk factors for increasing DALYs in 109 countries. $^{2}$

To address the prevalence of smoking in populations living in Iran, so far a number of studies have sporadically investigated this topic. ${ }^{10}$ In one of the studies, the prevalence of smoking was estimated to be $12 \%$ (23.4\% in males and $1.4 \%$ in females). ${ }^{11,12}$ None of the mentioned studies has addressed the prevalence of smoking among different age and sex groups in different provinces. To the best of our knowledge, the WHO has designed a STEPwise approach for the surveillance of risk factors such as smoking in different countries. The objective of this study is to provide a standardized method for obtaining reliable information on the crude and standardized prevalence of current, ever, and secondhand smoking at national and provincial levels, to help policy makers to build tools for the surveillance of diseases.

\section{Material and Methods}

Data Sources

This study was conducted through the analysis of the results of STEPs survey 2016 that was a cross-sectional national study carried out by the Non-Communicable Diseases Research Center (NCDRC). The samples were selected via multistage cluster sampling and they were representative of general population aged $\geq 18$ years living in all provinces of Iran. Using information technology tools, the STEPs 2016 met the standards to achieve the highest level of accuracy in design, sampling, implementation, data collection, and data cleaning. The study had three main parts, as follows: first, interviewing the subjects and administration of the questionnaire; second; laboratory measurements; and third, physical and anthropometry measurement. Details on this survey are published in the study protocol. ${ }^{13}$

To assess the self-reported prevalence of smoking among the Iranian population, some questions were asked from the participants (e.g. "have you ever smoked?", "have you ever smoked tobacco every day?", "Have you already smoked tobacco?", "do you smoke cigarettes every day", "how many cigarettes do you smoke during the day?", "at what age did you start smoking?", "do you use hookah every day?", "have you been exposed to smoking (smoked by other people) in your workplace during the past month?", "have you been exposed to smoking by other people in your home during the past month?, and "how many days per week do you smoke at work in your office?").

In order to assess the history of ever smoking, the subjects were asked the following question: "have you ever smoked?" Those who negatively responded to this question were assumed as people who had never smoked. The prevalence of secondhand smoking was assessed through considering the responses to the last two questions. The positive responses were merged using "OR".

\section{Statistical Analysis}

All the collected data were analyzed via survey analysis while considering the population weights. Age-standardized prevalence was also calculated based on the Iranian national population 2016 and the WHO Population 2000-2025 to yield comparable results for all the provinces. There were two weights for analyzing STEPs data, including questionnaires weight and laboratory weight. Since in this study we only used questionnaire data, the questionnaire weight was applied.

\section{Results}

Of a total of 30541 subjects aged $\geq 18$ to 100 years who participated in STEPs 2016, 29963 subjects had a complete profile of smoking status (missing data was $1.9 \%$ ). In total, $47.9 \%$ were male (Supplementary file 1, Table S1).

The crude prevalence of ever tobacco smoking in total population, in males, and in females aged $\geq 18$ years was $21.1 \%, 7.0 \%$, and $36.6 \%$, respectively. The prevalence of ever cigarette smoking in females and males was $1.8 \%$ and $28.6 \%$, respectively. The crude prevalence of current tobacco smoking in total adult population, males, and females was $14.2 \%, 25.2 \%$, and $4.0 \%$, respectively. The crude prevalence of current daily cigarette smoking was $10.1 \%(0.9 \%$ in females and $20.1 \%$ in males), which means 5825758 male individuals and 256470 female individuals among the Iranian population are smoking cigarettes daily. The prevalence of secondhand smoking was $26.3 \%$ at home and $14.5 \%$ in workplace. In addition, the prevalence of secondhand smoking regardless of location was $31.5 \%$ among the adult population. The total prevalence of using hookah was $0.2 \%$ in general adult population (Table 1).

Furthermore, the crude prevalence of past smoking was $20.1 \%$ (6.5\% among females and 35.0\% among males). Moreover, the age-sex-standardized prevalence rates based on the Iranian population in 2016 are presented in Table 1.

Concerning the prevalence of ever smoking in rural and urban areas, the crude prevalence was $21.86 \%(20.99 \%$ $-22.77 \%)$ in rural areas and $19.62 \%(19.06 \%-20.19 \%)$ in urban areas (Table S2). Furthermore, the prevalence of passive smoking in rural areas was $39.95 \%(38.87 \%-$ $41.04 \%)$ and in urban areas was $28.60 \%(27.96 \%-$ $29.25 \%$ ) (Table S3).

The prevalence of current cigarette smoking increased from $2.3 \%$ in people aged $18-24$ years to $14.5 \%$ in people aged $45-54$ years and then decreased gradually to $8.4 \%$ in 


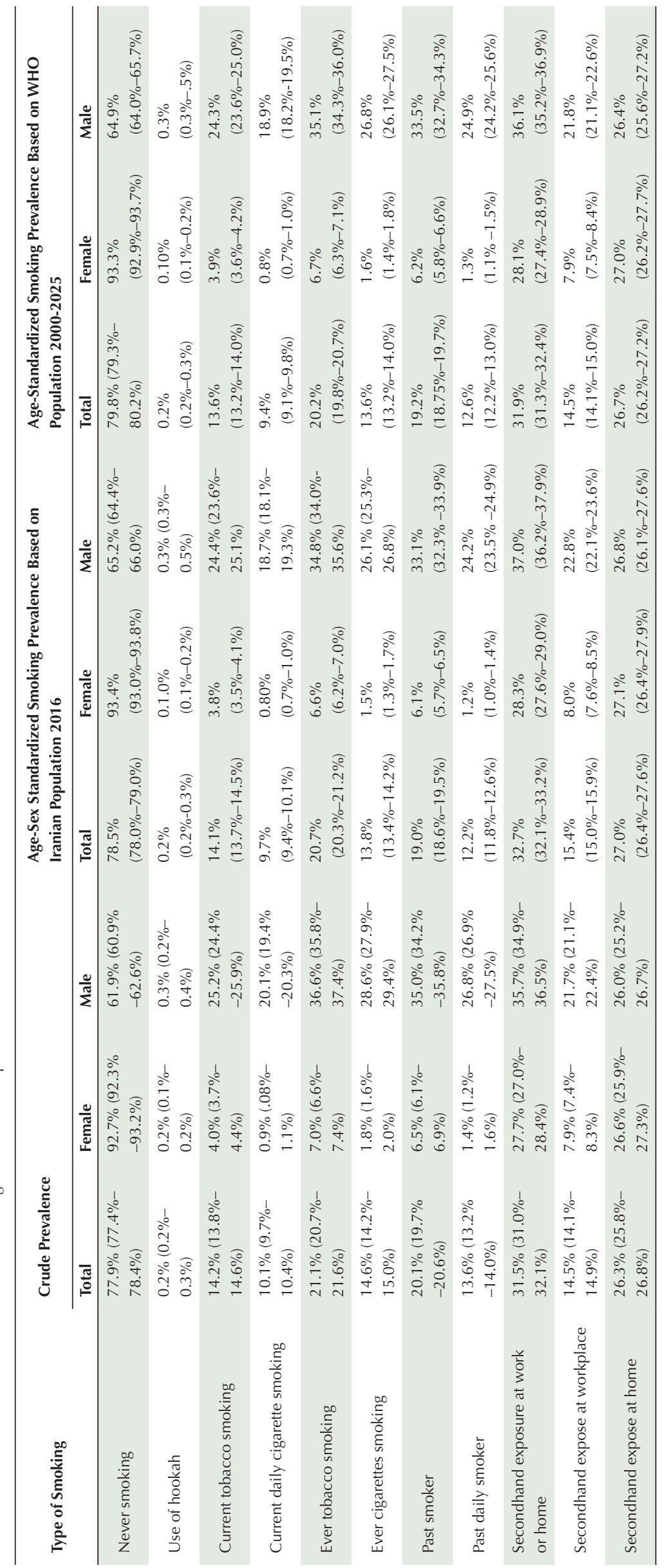


Table 2. Prevalence of Different Types of Smoking Among Age Groups

\begin{tabular}{|c|c|c|c|c|c|c|c|c|}
\hline $\begin{array}{l}\text { Age } \\
\text { Groups }\end{array}$ & ender & $\begin{array}{c}\text { Never } \\
\text { Smoking(\%) }\end{array}$ & $\begin{array}{c}\text { Current Tobacco } \\
\text { Smoking (\%) }\end{array}$ & $\begin{array}{l}\text { Current Cigarette } \\
\text { Smoking (\%) }\end{array}$ & $\begin{array}{c}\text { Ever Tobacco } \\
\text { Smoking } \\
(\%) \\
\end{array}$ & $\begin{array}{l}\text { Ever Cigarettes } \\
\text { Smoking (\%) }\end{array}$ & $\begin{array}{l}\text { Secondhand } \\
\text { Smoking (\%) }\end{array}$ & $\begin{array}{c}\text { Use of Hookah } \\
(\%)\end{array}$ \\
\hline \multirow{3}{*}{$\begin{array}{l}18-24 \\
\text { years }\end{array}$} & Male & $80.2(77.7-82.4)$ & $13.5(11.6-15.6)$ & $4.9(3.8-6.4)$ & $19.8(17.6-22.3)$ & $7.3(5.9-9)$ & $38.3(35.5-41.1)$ & $0.4(0.2-1.1)$ \\
\hline & Female & $95.7(94.5-96.6)$ & $2(1.4-2.9)$ & $0.1(0-0.5)$ & $4.3(3.4-5.5)$ & $0.4(0.1-0.9)$ & $31.9(29.5-34.4)$ & $0.1(0-0.5)$ \\
\hline & Total & $88.5(87.2-89.7)$ & $7.3(6.3-8.4)$ & $2.3(1.8-3.0)$ & $11.5(10.3-12.8)$ & $3.6(2.9-4.4)$ & $34.8(33.03-36.7)$ & $0.2(0.1-0.6)$ \\
\hline \multirow{3}{*}{$\begin{array}{l}25-34 \\
\text { years }\end{array}$} & Male & $68.4(66.7-70)$ & $22.5(21.1-24)$ & $14.6(13.5-15.9)$ & $31.6(30-33.3)$ & $19(17.7-20.4)$ & $41.2(39.5-42.9)$ & $1.1(0.8-1.6)$ \\
\hline & Female & $94.1(93.3-94.8)$ & $3.3(2.8-4)$ & $0.5(0.4-0.9)$ & $5.9(5.2-6.7)$ & $0.8(0.6-1.2)$ & $28.7(27.3-30.2)$ & $0.1(0-0.3)$ \\
\hline & Total & $82(81-82.9)$ & $12.4(11.6-13.2)$ & $7.2(6.6-7.9)$ & $18.0(17.1-19.0)$ & $9.4(8.7-10.1)$ & $34.6(33.52-35.7)$ & $0.6(0.4-0.8)$ \\
\hline \multirow{3}{*}{$\begin{array}{l}35-44 \\
\text { years }\end{array}$} & Male & $62(60.2-63.8)$ & $28.7(27.1-30.3)$ & $24.4(22.8-26)$ & $38(36.2-39.8)$ & $31.6(29.9-33.3)$ & $40(38.2-41.8)$ & $0.8(0.5-1.2)$ \\
\hline & Female & $93.8(92.9-94.6)$ & $4(3.4-4.8)$ & $0.6(0.4-1)$ & $6.2(5.4-7.1)$ & $1.2(0.9-1.7)$ & $29.9(28.4-31.5)$ & $0.2(0.1-0.4)$ \\
\hline & Total & $78.4(77.4-79.4)$ & $15.9(15.0-16.9)$ & $12.1(11.3-13.0)$ & $21.6(20.6-22.6)$ & $15.9(15.0-16.8)$ & $34.78(33.6-36.0)$ & $0.4(0.3-0.7)$ \\
\hline \multirow{3}{*}{$\begin{array}{l}45-54 \\
\text { years }\end{array}$} & Male & $56.5(54.5-58.4)$ & 32.7 (30.9-34.6) & $29.2(27.4-31)$ & $43.5(41.6-45.5)$ & $38.7(36.8-40.6)$ & $34.3(32.4-36.1)$ & $0.3(0.1-0.6)$ \\
\hline & Female & $92.5(91.5-93.5)$ & $5.1(4.4-6)$ & $1.3(1-1.8)$ & $7.5(6.5-8.5)$ & $1.8(1.4-2.4)$ & $27.3(25.7-28.9)$ & $0.3(0.1-0.5)$ \\
\hline & Total & $75.4(74.2-76.6)$ & $18.2(17.2-19.3)$ & $14.5(13.6-15.5)$ & $24.6(23.4-25.8)$ & $19.3(18.3-20.4)$ & $30.6(29.4-31.8)$ & $0.3(0.2-0.5)$ \\
\hline \multirow{3}{*}{$\begin{array}{l}55-64 \\
\text { years }\end{array}$} & Male & $54.8(52.6-57)$ & $29.4(27.5-31.5)$ & $25.5(23.7-27.5)$ & $45.2(43-47.4)$ & $39.8(37.7-42)$ & $31.4(29.4-33.4)$ & $0.6(0.3-1.1)$ \\
\hline & Female & $92.4(91.2-93.4)$ & $4.4(3.6-5.4)$ & $1.3(0.9-1.9)$ & $7.6(6.6-8.8)$ & $2.6(2-3.4)$ & $25.4(23.6-27.2)$ & $0.2(0.1-0.5)$ \\
\hline & Total & $74.4(73-75.7)$ & $16.4(15.3-17.6)$ & $12.9(11.9-14.0)$ & $25.6(24.3-27.0)$ & $20.4(19.2-21.7)$ & $28.2(26.9-29.6)$ & $0.4(0.2-0.6)$ \\
\hline \multirow{3}{*}{$\begin{array}{l}65-69 \\
\text { years }\end{array}$} & Male & $62.4(58.5-66.1)$ & $20(17-23.4)$ & $17.7(14.9-21)$ & $37.6(33.9-41.5)$ & $33.1(29.5-37)$ & $24.2(21-27.7)$ & $0.8(0.3-2.1)$ \\
\hline & Female & $90.5(88.2-92.4)$ & $4.5(3.2-6.2)$ & $1.3(0.7-2.4)$ & $9.5(7.6-11.8)$ & $3.9(2.7-5.6)$ & $23.2(20.4-26.3)$ & $0.7(0.3-1.7)$ \\
\hline & Total & $77.8(75.5-80)$ & $11.5(9.9-13.3)$ & $8.7(7.3-10.3)$ & $22.2(20.0-24.5)$ & $17.1(15.2-19.2)$ & $23.6(21.5-25.9)$ & $0.8(0.4-1.4)$ \\
\hline \multirow{3}{*}{$\begin{array}{l}70+ \\
\text { years }\end{array}$} & Male & $64.5(61.9-67.1)$ & $16.8(14.8-18.9)$ & $13.9(12.1-15.9)$ & $35.5(32.9-38.1)$ & $28.7(26.3-31.2)$ & $23.8(21.6-26.2)$ & $1(0.6-1.7)$ \\
\hline & Female & $88(86-89.8)$ & $5.3(4.1-6.7)$ & $2.2(1.5-3.3)$ & $12(10.2-14)$ & $5.1(3.9-6.6)$ & $21.2(18.9-23.7)$ & $0.4(0.1-1)$ \\
\hline & Total & $75.6(73.8-77.3)$ & $11.4(10.2-12.7)$ & $8.4(7.3-9.6)$ & $24.4(22.7-26.2)$ & $17.6(16.1-19.2)$ & $22.6(21.0-24.3)$ & $0.7(0.4-1.1)$ \\
\hline
\end{tabular}

people aged over 70 years. With increase in the participants' age, the prevalence of secondhand smoking decreased from $34.8 \%$ among people aged $18-24$ years to $22.6 \%$ in people aged over 70 years (Table 2) (Supplementary file 2, Figure S1). The age trend of cigarette prevalence in Iran is shown in Figure 1. Furthermore, the status of current cigarettes smoking and past cigarette smoking among provinces in Iran by sex, 2016 are shown in Figures S2 and S3.

The mean number of cigarettes smoked per day in currently smoking subjects was 10.35 (9.87-10.83) cigarettes per day. Moreover, 24.1\% (22.5\%-25.7\%) of the subject were smoking a maximum of five cigarettes per day, $23.1 \%$ (21.6\%-24.7\%) were smoking 6-10 cigarettes

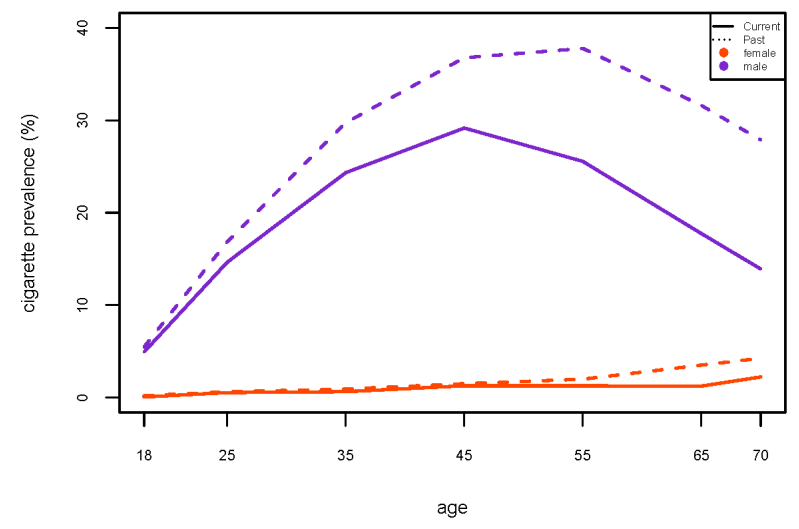

Figure 1. Age Trend of Cigarette Prevalence in Iran per day, $8.3 \%(7.3 \%-9.4 \%)$ were smoking $11-15$ cigarettes per day, 35.0\% (33.2\%-36.8\%) were smoking 16-20 cigarettes per day, and $9.6 \%(8.5 \%-10.7 \%)$ were smoking more than 20 cigarettes per day.

The mean starting age of the participants for smoking was $21.56(21.11-22.01)$ years in the general population, 21.25 (20.82-21.68) years in males, and $27.65(24.14$ 31.15 ) years in females. Moreover, $10.1 \%$ (8.5\%-11.9\%) of the participants started smoking when they were under 15 years, $34.1 \%(31.6 \%-36.8 \%)$ at the age of $15-19$ years, $46.1 \%(43.4 \%-48.9 \%)$ at the age of $20-30$ years, and $9.6 \%(8.1 \%-11.4 \%)$ at the age of over 30 years.

Of those who smoked cigarette, $26.1 \%$ (24.6\%-29.2\%) had been smoking cigarettes for 12 months before the interview. Overall, $18.7 \%$ of the studied population had a history of quitting smoking for at least once (Table S4).

There was a significant difference between different provinces of Iran in terms of the prevalence of cigarettes smoking. The highest prevalence rates of current cigarette smoking were observed in West Azarbaijan with 14\% (12.3\%-16\%) and Markazi with 13.7\% (11.2\%-16.7\%) and the lowest prevalence rates were observed in North Khorasan with $4.7 \%(3.4 \%-6.5 \%)$ and Golestan with 5\% $(3.6 \%-7 \%)$ (Table 3).

\section{Discussion}

This study, as a large national study, provided new reliable information about the prevalence of smoking among the 


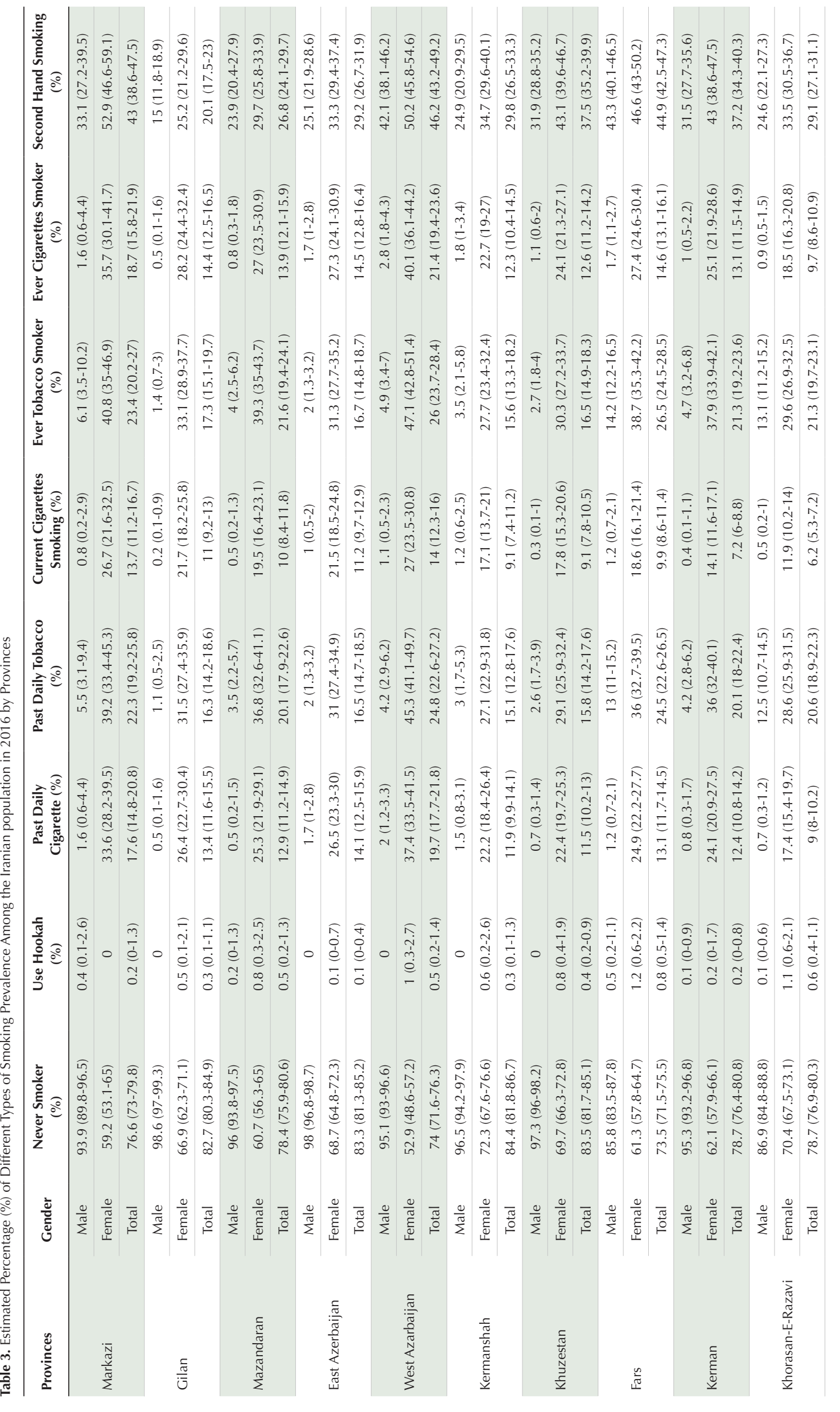




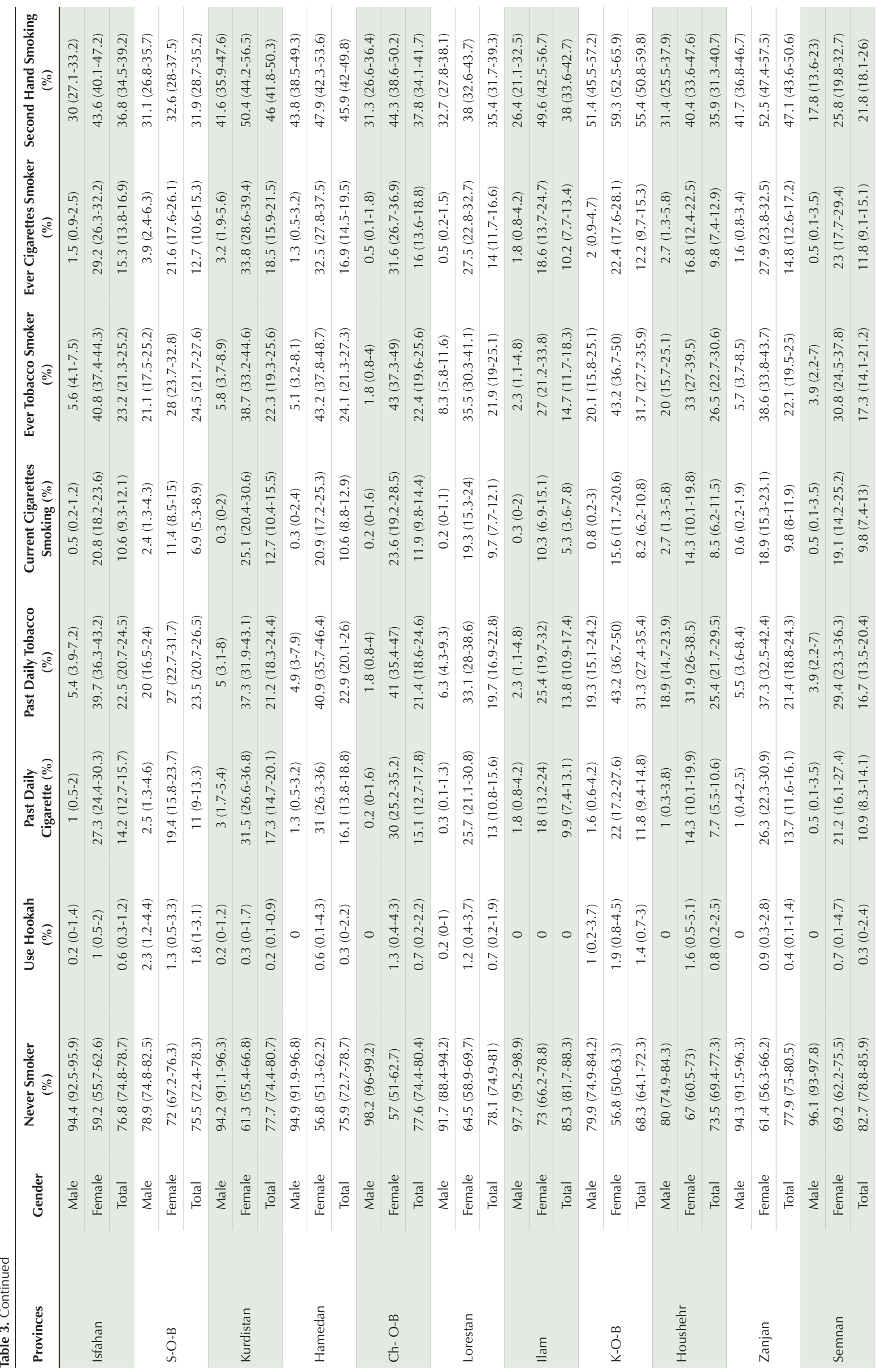




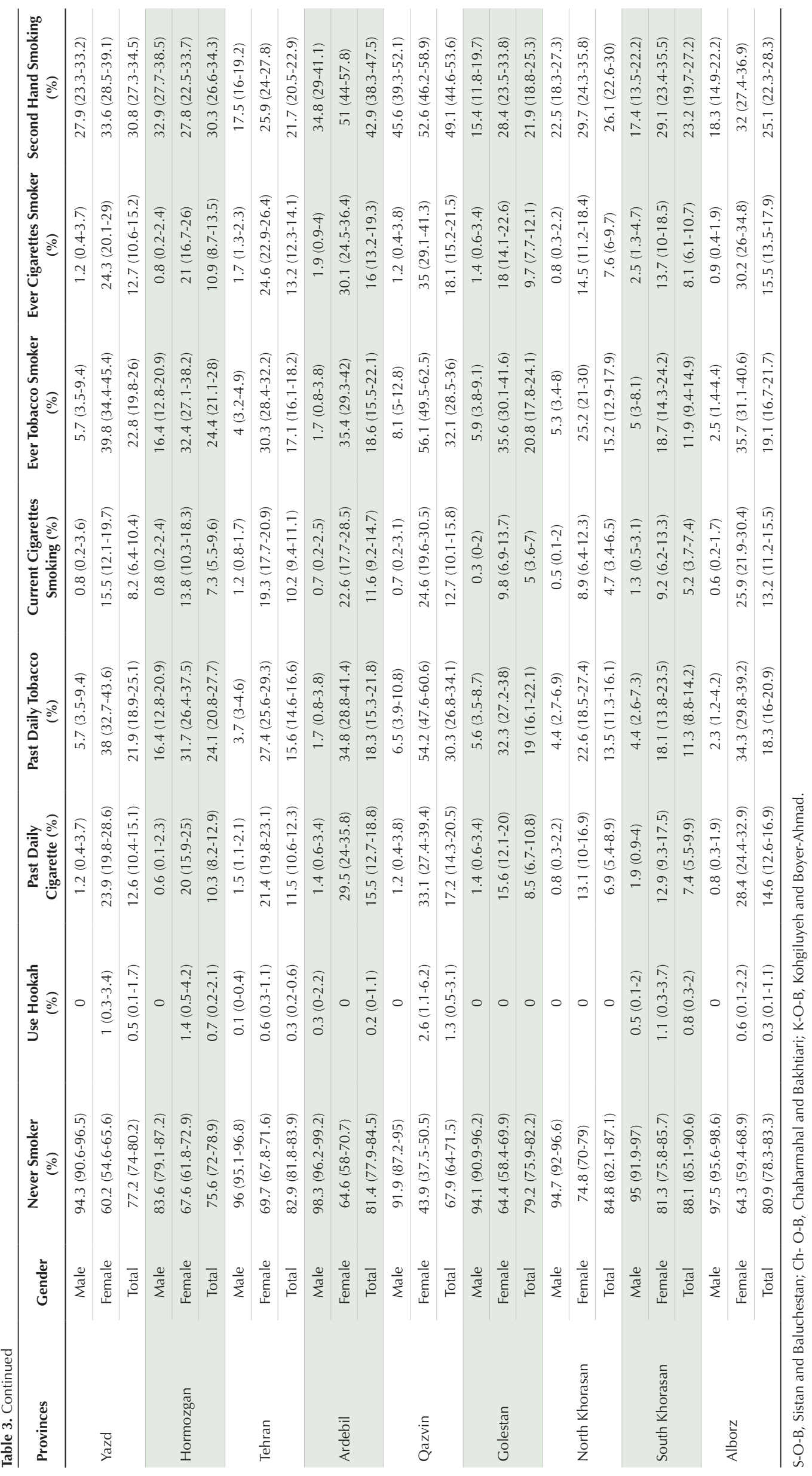


Iranian population in 2016. We found that more than $15 \%$ of the Iranian population were currently smokers for all types of tobacco and a little less than one of ten Iranians were current cigarette smokers. In contrast, more than three-fourths of the Iranian population never smoked. Considering sex difference, apparently, there was a huge discrepancy between males and females in terms of the prevalence of smoking. Therefore, the prevalence of current cigarette smoking in males was about 20 times higher than that in females and it was 6 times larger in terms of current smoking. The prevalence of smoking in people aged 18 years and over in both sexes increased with aging and reached the peak in people aged 45-54 years old then decreased. The results of a study by Emami et al are consistent with our findings. ${ }^{14}$ Two systematic review studies in Iran reported the prevalence of current smoking which ranged from $0.6 \%$ to $9.8 \%$ among females ${ }^{15,16}$ and from $12.3 \%$ to $38.5 \%$ among males. ${ }^{16}$ In another systematic review in one of the northern provinces of Iran, it was reported that the pool prevalence of current smoking was $12.1 \%$ (23.4\% among males and $0.9 \%$ among females). ${ }^{17}$ As reported by the WHO, the prevalence of current smoking was $11 \%$ in India, 17.5\% in Saudi Arabia, ${ }^{18}$ 26.2\% in Thailand and 26.9\% in Turkey. ${ }^{19}$ Tobacco smoking imposes a huge economic burden on health systems in the world, and smoking control can decrease the cost and death rate of NCDs in communities. ${ }^{20}$

We found that the mean number of cigarettes smoked by current cigarettes smokers was 10.3 per day. Taking into consideration the prevalence of current smoking and the population of Iran in 2016, it seems that more than 80 million cigarettes daily and about 30 billion cigarettes annually are smoked in Iran, i.e. 365 cigarettes per person in Iran.

Concerning secondhand smoking, about one third of the Iranian population are exposed to secondhand smoking; it is more than one third in males. However, such a difference between males and females was not observed in secondhand smoking at home. With increasing education levels and decreasing age, secondhand smoking deceased. Moreover, it is more prevalent in rural than urban areas. Nevertheless, second hand smoking had no relationship with income. This difference in the prevalence of smoking by education level and area of residence may be justified by higher levels of awareness among people with higher levels of education and among those who live in urban areas, as compared with those with lower education level and those living in rural areas. In a study in one province, the prevalence of passive smoking was estimated to be about $27.5 \%$; it was more prevalent among females than males. ${ }^{21}$ Another study in Iran reported that the prevalence of passive smoking was $6.2 \%$ and $0.6 \%$ among males and female, respectively. ${ }^{21}$

Concerning smoking cessation, we found that during the 12 months before the study, more than one fourth of the smokers had a history of quitting at least once. In STEPs 2016, the researchers did not ask about the rate of successful cessation of smoking. There was not a significant difference between the two sexes. Our results are in line with the rates reported by another study. ${ }^{21}$

According to the results of the study, some factors affected the variability of tobacco smoking prevalence in different provinces of Iran. We observed that the years of schooling and the levels of income were related to smoking rates. Along with the increase in education level among the participants of the study, tobacco smoking decreased. In addition, the residents of provinces with higher income levels were more likely to smoke. The examples are West Azarbaijan and Markazi provinces. Of course, the culture band and urbanization might be related to the inconsistencies in smoking prevalence among provinces.

In this study, we faced some limitations. As a potential limitation of this study, all data on the prevalence of smoking was collected through using a self-reported questionnaire without any biomedical marker. We reported the mean starting age of the participants for smoking in this study. However, it seems that our study faced potential biases such as recall bias because the participants of study might have forgotten the time of onset. In addition, the participants were older than 18 , so the onset of smoking in this study might be reported higher than the reality. The main strength of this study was the use of a large sample size, which can be representative of all Iranian population. Moreover, our results showed the prevalence of smoking among all socioeconomic population groups such as the young and adults, educated and uneducated people, etc. Thus, we were able to determine important factors which influenced the prevalence of smoking in Iran. Furthermore, this study had very little missing data (less than 2\%), because the required data were gathered by electronic and online tools. The program was designed in a way that led nobody to go to the next questions without giving a response to previous ones, hence the missing data was due to technical problems in transferring the data, and was not related to the lack of responses. Hence, we think the missing data were random. On the other hand, the sample size was calculated in a way to be $10 \%$ larger than the required sample size to address the missing data. Therefore, the missing data did not violate the generalizability of the data.

In conclusion, this study demonstrated the prevalence of several types of tobacco and cigarettes smoking patterns among the Iranian population. The results of the study can be used to inform policy makers about the status of smoking and help them to design policies for setting rules on and limiting the import of cigarettes and their components to the country. Furthermore, these results help them to identify high-risk population groups among all age groups, education levels, etc. 


\section{Authors' Contribution}

FF designed the study. MV, FSH, PM, ASH, SHJ, KG, MM, FP, NP, $\mathrm{RH}, \mathrm{AKH}$, and $\mathrm{HZ}$ collected the data. FSH, MV, PM, and ASH did the demographic analysis. FF, FSH, PM, ASH, and MV did the statistical analysis. MV and FSH wrote the first draft. FF, MV, FSH, $\mathrm{PM}, \mathrm{ASH}, \mathrm{KG}, \mathrm{SHD}, \mathrm{AKH}, \mathrm{HZ}, \mathrm{NP}, \mathrm{GHM}, \mathrm{ARM}$, and FP interpreted the results. FF, MV, FSH, PM, ASH, GHM, MM, and SHD revised the final draft.

\section{Conflict of Interest Disclosures}

The authors have no conflicts of interest.

\section{Ethical Statement}

This study was approved by the Ethical Committee of National Institute for Medical Research Development (NIMAD) (ID: IR.NIMAD.REC.1394.032) and all the phases of the study were under the stewardship of ethical committee of this institute. An informed consent form was signed by all the participants before enrollment in the study.

\section{Supplementary Materials}

Supplementary file 1 contains Tables S1-S4 and Supplementary file 2 cotains Figures S1-S3.

\section{References}

1. Peykari N, Hashemi H, Dinarvand R, Haji-Aghajani $M$, Malekzadeh R, Sadrolsadat A, et al. National action plan for non-communicable diseases prevention and control in Iran; a response to emerging epidemic. J Diabetes Metab Disord. 2017;16(1):3. doi: 10.1186/s40200-017-0288-4.

2. Forouzanfar MH, Afshin A, Alexander LT, Aasvang GM, Bjertness E, Htet AS, et al. Global, regional, and national comparative risk assessment of 79 behavioural, environmental and occupational, and metabolic risks or clusters of risks, 1990-2015: a systematic analysis for the Global Burden of Disease Study 2015. Lancet. 2016;388(10053):1659-1724. doi: 10.1016/S0140-6736(16)31679-8.

3. Farzadfar F, Danaei G, Namdaritabar H, Rajaratnam JK, Marcus JR, Khosravi A, et al. National and subnational mortality effects of metabolic risk factors and smoking in Iran: a comparative risk assessment. Popul Health Metr. 2011;9(1):55. doi: 10.1186/1478-7954-9-55.

4. United Nations. Political declaration of the High-level Meeting of the General Assembly on the Prevention and Control of Non-communicable Diseases. Accessed Date: March 10, 2017. Available from: https://digitallibrary.un.org/ record/710899/? In=en.

5. Benziger CP, Roth GA, Moran AE. The global burden of disease study and the preventable burden of NCD. Glob Heart. 2016;11(4):393-7. doi: 10.1016/j.gheart.2016.10.024.

6. World Health Organization. WHO global report on trends in prevalence of tobacco smoking 2015. Available from: https:// apps.who.int/iris/handle/10665/156262.

7. World Health Organization. Tobacco. Accessed: 26 July 2019.
Available from: https://www.who.int/news-room/fact-sheets/ detail/tobacco.

8. Lopez AD, Mathers CD, Ezzati M, Jamison DT, Murray CJ. Global and regional burden of disease and risk factors, 2001: systematic analysis of population health data. The Lancet. 2006;367(9524):1747-57. doi: 10.1016/S01406736(06)68770-9.

9. Oh I, Yoon S, Tai-Young, Choi J, Bong-Keun, Kim E, et al. Health and economic burden of major cancers due to smoking in Korea. Asian Pac J Cancer Prev. 2012;13(4):1525-31. doi: 10.7314/apjcp.2012.13.4.1525.

10. Ahmadi J, Khalili H, Jooybar R, Namazi N, Mohammadagaei P. Prevalence of cigarette smoking in Iran. Psychol Rep. 2001;89(2):339-41. doi: 10.2466/pr0.2001.89.2.339.

11. Meysamie A, Ghaletaki R, Haghazali M, Asgari F, Rashidi A, Khalilzadeh $\mathrm{O}$, et al. Pattern of tobacco use among the Iranian adult population: results of the national Survey of Risk Factors of Non-Communicable Diseases (SuRFNCD-2007). Tob Control. 2010;19(2):125-8. doi: 10.1136/tc.2009.030759.

12. World Health Organization. WHO Report on the Global Tobacco Epidemic, 2008. The MPOWER package. Available from: https://www.who.int/tobacco/mpower/gtcr_download/ en/.

13. Djalalinia S, Modirian $M$, Sheidaei A, Yoosefi M, Zokaiee $H$, Damirchilu B, et al. Protocol Design for Large-Scale CrossSectional Studies of Surveillance of Risk Factors of NonCommunicable Diseases in Iran: STEPs 2016. Arch Iran Med. 2017;20(9):608-16. doi: 0172009/AIM.009.

14. Emami H, Habibian S, Salehi P, Azizi F. Pattern and smoking habit in an urban area in Tehran, 2001. Research in Medicine. In Persian. 2003;27(1):47-52.

15. Halimi L, Haghdoost AA, Alizadeh SM. Prevalence of cigarette smoking among Iranian women: a systematic review and meta-analysis. Med J Islam Repub Iran. 2013;27(3):132-40.

16. Moosazadeh $M$, Ziaaddini $H$, Mirzazadeh A, AshrafiAsgarabad A, Haghdoost AA. Meta-analysis of smoking prevalence in Iran. Addict Health. 2013;5(3-4):140-53.

17. Moosazadeh M, Amiresmaili M, Afshari M. Individual Patient Data Meta-Analysis of the Smoking Prevalence in Mazandaran Province of Iran. Iran Red Crescent Med J. 2015;17(2): e10294. doi: 10.5812/ircmj.10294.

18. Bassiony MM. Smoking in Saudi Arabia. Saudi Med J. 2009;30(7):876-81.

19. Public Health Institution of Turkey. Global Adult Tobacco Survey Turkey 2012. Available from: https://www.who.int/tobacco/surveillance/survey/gats/report_tur_2012.pdf?ua =1 .

20. Varmaghani $M$, Kebriaeezadeh A, Sharifi F, Sheidaei A, Rashidian A, Moradi-Lakeh M, et al. Death Specific Rate Due to Asthma and Chronic Obstructive Pulmonary Disease in Iran. Clin Respir J. 2018;12(6):2075-2083. doi: 10.1111/ crj. 12776 .

21. Eftekhar Ardebili M, Nassr M, Rassulian M, Ghalebandi MF, Daneshamuz B, Salehi M. Prevalence of Cigarette Smoking in Tehran: A household study. IJPBS. 2007;1(2):33-7. 